\title{
A randomised controlled trial of student nurse performance of cardiopulmonary resuscitation in a simulated family-witnessed resuscitation scenario
}

Gerard Kenny, Isabelle Bray, David Pontin, Rachel Jefferies, John Albarran

\section{$\underline{\text { ABSTRACT }}$}

This randomized controlled trial, conducted in a UK University nursing department, compared student nurses' performance during a simulated cardiac arrest. Eighteen teams of four students were randomly assigned to one of three scenarios: 1) no family witness; 2) a "quiet" family witness; and 3) a family witness displaying overt anxiety and distress. Each group was assessed by observers for a range of performance outcomes (e.g. calling for help, timing to starting cardiopulmonary resuscitation), and simulation manikin data on the depth and timing of three cycles of compressions. Groups without a distressed family member present performed better in the early part of the basic life support algorithm. Approximately a third of compressions assessed were of appropriate pressure. Groups with a distressed family member present were more likely to perform compressions with low pressure. Groups with no family member present were more likely to perform compressions with too much pressure. Timing of compressions was better when there was no family member present. Family presence appears to have an effect on subjectively and objectively measured performance. Further study is required to see how these findings translate into the registered nurse population, and how experience and education modify the impact of family member presence. 


\section{HIGHLIGHTS}

- $\quad$ Simulation enables student nurses to practice BLS skills in a safe environment - In this RCT, family presence was found to affect the performance of CPR by student nurses

- $\quad$ Approximately a third of compressions performed were of appropriate pressure

- $\quad$ Groups with no family member present were more likely to perform compressions with too much pressure

- $\quad$ Timing of compressions was better when there was no family member present

Key words: Family-witnessed resuscitation, student nurses, simulation, randomised controlled trial 


\section{INTRODUCTION}

\section{The Family Witnessing Context}

It is now over thirty years since the first tentative steps to facilitate the presence of family members during resuscitation. The early work and evaluations have framed the themes that influenced subsequent debates, which can be identified as three core narratives (Hanson and Strawser, 1992). The first core narrative is concern for distress caused to relatives by being present, the second relates to anxiety that relatives could interfere with resuscitation attempts, and finally, the impact of being observed on health professional performance (Halm, 2005; Critchell and Marik, 2007; Chapman et al. 2012). The first two themes are briefly illustrated to set the context so that we can explore the third theme (the effect on performance) in detail.

\section{Distress for relatives}

The first narrative articulated by healthcare professionals is that being present and observing loved ones undergoing cardiopulmonary resuscitation (CPR) might be adversely distressing and harm relatives (Basol et al., 2009; Walker, 2008). Meyers et al.'s (2000) literature review identifies two themes that offer an alternative perspective. Firstly, relatives feel connected to their family member during resuscitation and derive emotional benefit if present. Even when resuscitation was unsuccessful, relatives reported that this experience helped them understand the experience and their grieving. Recently, Jabre et al.'s (2013) randomised controlled trial highlighted that family presence during CPR compared to family absence was associated with positive results for well-being against a criteria of psychological variables post-traumatic stress disorder, anxiety and depression. The evidence around children 
undergoing resuscitation with parental presence further augments the adult-patient literature. Strong qualitative studies report that families and carers experienced great comfort and coped better with grieving having been present at their child's resuscitation (McGahey et al. 2007; Tinsley et al. 2008). The second counter-argument to professional anxiety about relatives' distress when witnessing resuscitation concerns family rights. Family members increasingly consider that they have a right to be with their family member. This reflects the shift in power between healthcare professionals and patients. Patients are moving from being passive recipients to active consumers of healthcare, with expectations of partnership working and shared decision making (Coulter and Collins, 2011; Legare and Witteman, 2013).

\section{$\underline{\text { Interference by Relatives }}$}

The second healthcare professional narrative is that family members could interfere and disrupt resuscitation (Demir, 2008; Fernandez et al., 2009). There is some evidence that nurses have experienced physical and verbal abusive, and violence from family members directed towards the resuscitation team (Koberich et al. 2010). Most of the counterevidence draws on child and family literature, but in key studies there is no evidence to support concerns that family member presence during resuscitation hampers, interferes or prolongs the event (Nigrovic et al.,2009; Basol et al., 2009). This literature challenges healthcare professionals' key anxieties and concerns about jeopardising patient and relative well-being. There is also anxiety about potential litigation if family members witness a poor outcome (Madden \& Condon, 2007; McClement et al., 2009). However, there is no evidence of increased litigation in any country so far (Jabre et al. 2013; Boyd 2000). 


\section{Effect on performance}

The final narrative is that family member presence has an adverse impact on professionals' performance of CPR. There is little available data on this topic and it remains relatively under-explored. In child and family studies, there is limited evidence supporting decreased performance when family members are present for invasive procedures (Basol et al., 2009). These assumptions can be assessed using simulation with planned CPR scenarios. Bjørshol et al. (2011) used simulation with paramedics to test if socio-emotional stress affected CPR quality and found no effect of stress on quality of care delivered. However, Fernandez et al. (2009) found the opposite using a simulated scenario with a second and third-year emergency medicine resident cohort. They found distressed relative presence significantly delayed the time to deliver the first defibrillation shock. This was longer for the overt reaction witness group compared with no family witness groups. The groups with the distressed relative delivered fewer total shocks compared with the no family witness groups.

Attempts to research the impact of family member presence on healthcare professional CPR performance presents big challenges. Firstly, multiple causes of cardiac arrests make it difficult to randomise subjects into comparable groups. Secondly, prediction of family member response is impossible, so family member response cannot be controlled for under experimental conditions. The same relative might be quiet and withdrawn one moment and display overt signs of grief and distress the next, making it difficult to assess family member impact on healthcare team CPR performance. Finally, levels of experience and training between clinical teams in real-time clinical practice will not be the same which prevents direct comparisons between groups. Therefore, simulation is a useful tool to test the hypothesis that family presence affects nurses performance. 


\section{$\underline{\text { Simulation in nurse education }}$}

The use of simulation in nurse education has increased in the last decade in response to concerns about improving skills acquisition and retention, and enhancing learning experiences. The aim is to be consistent with clinical needs and practice, improve patient safety and address practice placement capacity issues i.e. number and quality of available placements (Health Education Training Institute, 2014). There has been a drive in the UK to articulate the key components of simulation based education through the Framework for Technology Enhanced Learning. This recognises that simulation allows students to engage with complex practice, refine new techniques and skills, and reflect on multifaceted concepts and ideas (DH, 2011).

There is very little work examining student nurses' performance during family presence at CPR. This is an important oversight as student nurses provide a significant portion of direct care and their proximity often requires them to recognise and initiate CPR in the event of cardiac arrest (Eikeland et al., 2012). To this end, we conducted a randomised controlled trial (RCT) to explore the impact of family member presence on student nurses' performance of Basic Life Support (BLS). The trial was consistent with the simulation pedagogy at a UK university nursing department, providing a rich learning opportunity for undergraduate nursing students to practice making real-time clinical decisions in an environment that posed no risk to patients (Akhu-Zaheya et al 2012). 


\section{RESEARCH DESIGN}

\section{The randomised controlled trial}

A RCT was designed to assess whether family member presence had an impact on students' ability to perform Basic Life Support (BLS) tasks in keeping with their training stage. Following Fernandez et al. (2009), students were randomised to one of three simulated scenarios: (1) no family member present, (2) a quiet family member present and (3) a distressed family member present. Resuscitation training experts reviewed the scenarios for relevance and application. Teams of four students resuscitated a programmed manikin following one of the scenarios. All three manikins were programmed to deteriorate in the same way. Actors played the part of family members and were prepared in advance to be consistent in their roles. Observers were present in each scenario to record outcome data, but did not take part in any way or seek to influence student performance.

\section{Ethics}

The research team and student sample were members of the same academic institution and the study took place in dedicated timetabled teaching time. Therefore, steps were taken to prevent student coercion and to maximise the benefits of student participation. The study received approval from the Faculty Research Ethics Committee. A study team member not involved directly in student teaching briefed the students four weeks in advance. This was sufficient time for students to read the Participant Information Sheets, and raise any questions or concerns so that they could provide free and voluntary consent. Students and staff involved in the module were notified via a group email about follow-up forums for information and questions available in a virtual learning environment used for teaching. 
Students were informed that if they did not want participate in the study but wanted to be part of the educational experience this would be accommodated. Participants gave consent before they took part in the study. The study received funding from ASHiP and CAE healthcare who produce manikins. However, the human patient simulators used in the study were made by a different company (Gaumard) so there was deemed to be no conflict of interest.

\section{Sample and randomisation}

Eligible students were all second year undergraduate adult nursing students based on two sites and at the same training stage. All students were taking a clinical practice-based module when the research took place. All students had passed their mandatory annual training in BLS three weeks prior to the test taking place to minimise poor skills retention post BLS training (Abella, et al 2005; Leighton, Scholl, 2009). No exclusions were made, but students were advised that they may prefer not to take part if the had experienced recent death or difficult diagnosis of family/friend. Each of the three scenarios was populated by four randomly assigned recruited students. Randomisation was achieved by randomly ordering the student lists and selecting the first four as group 1, and so on.

\section{Data collection}

The Gaumard Advanced Patient simulators (HAL® S3201; Miami, Florida) were tested prior to use by staff technicians, and calibrated by Gaumard representatives to ensure validity and reliability. Manikin software recorded performance with airway, chest compressions, and ventilation breaths for the first three CPR cycles (i.e. 90 compressions), according to the 
scenario protocol. In discussion with the high fidelity manikin providers, a criterion for 'good pressure' was set at $150-200 \mathrm{mmHg}$ which was deemed to be sufficient to achieve the required compression depth. The criterion for 'good timing' for chest compression was occurrence in less than 0.5 seconds, sufficient for the number of recommended compressions to occur in one minute. Manikin ventilation data was provided as 'Low', 'OK' or 'High'.

Observational data was also collected from three observers (one for each scenario). Observers held resuscitation training officer status in clinical practice or were qualified to teach BLS. The criteria for assessing the observational data was based on the Resuscitation Council UK (2015) guidelines. Therefore, observers were experienced to generate consistency in their interpretation of student actions which dealt with the early part of the BLS algorithm - time to call for help, opening airway, checking for breathing and commencing compressions and ventilations.

\section{$\underline{\text { Statistical analysis }}$}

Manikin and observational data was exported to Excel for cleaning and analysis. Stata 12 was used to perform statistical tests (StataCorp, 2011). Unpaired t-tests tested for differences in number of compressions between groups and time to call for help. Fisher's exact tests tested for differences in proportions. 


\section{RESULTS}

\section{Participation}

All 79 students in the cohort attended the BLS update. Forty-eight of the 50 Bristol based students were randomly assigned to a group for each of the three scenarios. There were 12 groups, so each of the three possible scenarios was timetabled to run on four occasions, leaving two students in reserve. For Gloucester based students, 24 of the 29 students were randomly assigned to six groups - each scenario was timetabled twice leaving five students in reserve. Sixty-nine students attended the taught session on the day the educational intervention took place (recent bereavement may account for some non-attendance cases). All those who attended consented to take part in the trial $(10 \%$ consented in advance and the rest on the day).

Students took part in the scenario to which they were randomised, with the following exceptions. Firstly, six students (7.5\%) had restricted availability, so were swopped with other students to a different time slot (in three cases to the same scenario) to maximise the student participation numbers. Secondly, three students were randomised to a particular group but did not attend. This left three groups with three rather than four students performing CPR as a team (two in the no family member present scenario and one in the a quiet family member present scenario). Finally, a group randomised to the distressed family member scenario did not go ahead due to technical failure. Reserve students formed a sixth group for this scenario. So 18 groups took part in the study as planned (see Table 1) comprising a total of 69 students. 
Table 1 - Numbers of groups (each of 4 students) in each arm of the trial

\begin{tabular}{|lll}
\hline \multicolumn{1}{|c|}{ Scenario } & \\
\hline $\begin{array}{l}\text { Number of groups who took } \\
\text { part in the scenario }\end{array}$ & $\begin{array}{l}\text { 1: No family member } \\
\text { (two of these groups had } \\
\text { only 3 members) }\end{array}$ & $\begin{array}{l}6 \\
\text { (one of these groups had } \\
\text { only 3 members) }\end{array}$ \\
\hline $\begin{array}{l}\text { Number of groups for whom } \\
\text { manikin recorded } \\
\text { performance }\end{array}$ & 6 & 3 \\
\hline $\begin{array}{l}\text { Number of groups for whom } \\
\text { manikin arrested (observer } \\
\text { data collected) }\end{array}$ & 6 & 5 \\
\hline
\end{tabular}

\section{$\underline{\text { Manikin data }}$}

High-fidelity manikins are an invaluable addition to research and practice, but technical failure is possible and this study suffered from several such problems. Firstly, the manikin did not arrest in two groups (quiet family member scenario, and distressed family member present scenario). Observations of time taken to call for help and other basic checks were not made in these groups (see Table 1). Secondly, ventilation data recording was erratic and inconsistent. Observers noted that ventilations given were in keeping with the BLS algorithm, but the manikin software registered very few, sometimes none, so ventilation data was not analysed. Thirdly, the manikin used for groups with quiet family member present (scenario 2) failed to record and save compression data accurately (affecting three out of six groups) despite preparation and testing. Therefore, comparisons of compression data are restricted to scenario 1 and scenario 3 due to significant manikin data loss. 


\section{Compressions}

Table 2 shows data about compression pressure (too high/good/too low) and timing (good/poor) over the first three CPR cycles (90 compressions) for each scenario pooled across groups.

Table 2. Number (\%) of compressions of good pressure and good timing in each scenario

\begin{tabular}{|c|c|c|c|c|}
\hline \multicolumn{4}{|c|}{ Pressure } & \multirow{2}{*}{$\begin{array}{l}\text { Timing } \\
\text { Good }\end{array}$} \\
\hline Scenario & Too low & Good & Too high & \\
\hline $\begin{array}{l}\text { 1. No family } \\
\text { member present }\end{array}$ & $208(38 \%)$ & 155 (29\%) & $177(33 \%)$ & 459 (85\%) \\
\hline \multirow{2}{*}{$\begin{array}{l}\text { 3.Distressed } \\
\text { family member } \\
\text { present }\end{array}$} & 262 (49\%) & 197 (36\%) & 81 (15\%) & $423(78 \%)$ \\
\hline & \multicolumn{3}{|c|}{$\begin{array}{l}\text { Fishers exact test for association between } \\
\text { pressure and scenario } \\
p=0.000\end{array}$} & $\begin{array}{l}\text { Fishers exact test for } \\
\text { association between } \\
\text { timing and scenario } \\
p=0.000\end{array}$ \\
\hline
\end{tabular}

With no family member present, approximately a third of compressions were too low pressure (38\%), good pressure (29\%) and too high-pressure (33\%) respectively. When a distressed family member was present, less pressure tended to be applied. This resulted in more compressions being too low pressure (49\%), a slight increase in the proportion of compressions with good pressure (36\%), and a reduction in the number of too high-pressure compressions (15\%). Differences in compression pressure between the two scenarios were statistically significant $(p=0.000)$. A greater proportion of compressions had good timing when no family member was present ( $85 \%$ v $78 \% ; p=0.000)$. 


\section{Observer data}

Observer data of group performance after manikin arrest were manually recorded for six groups in scenario 1, and five groups in scenarios 2 and 3 . The number of groups who called for help, the average time taken call, and the number of groups who opened the airway, checked for breathing, did compressions and did ventilations is shown in Table 3. 
Table 3. Performance of groups in each scenario as assessed by observers

\begin{tabular}{|c|c|c|c|c|c|c|c|}
\hline Scenario & $\begin{array}{l}\text { Number of } \\
\text { groups } \\
\text { observed }\end{array}$ & $\begin{array}{l}\text { Number of } \\
\text { groups that } \\
\text { called for } \\
\text { help }\end{array}$ & $\begin{array}{l}\text { Average time } \\
\text { taken to call } \\
\text { for help } \\
\text { (seconds) }\end{array}$ & $\begin{array}{l}\text { Number of } \\
\text { groups who } \\
\text { opened } \\
\text { airway }\end{array}$ & $\begin{array}{l}\text { Number of } \\
\text { groups who } \\
\text { checked for } \\
\text { breathing }\end{array}$ & $\begin{array}{l}\text { Number of } \\
\text { groups who } \\
\text { did } \\
\text { compression }\end{array}$ & $\begin{array}{l}\text { Number of } \\
\text { groups who } \\
\text { did } \\
\text { ventilations }\end{array}$ \\
\hline $\begin{array}{l}\text { 1. No family } \\
\text { member } \\
\text { present }\end{array}$ & 6 & 3 & 33 & 5 & 5 & 6 & 6 \\
\hline $\begin{array}{l}\text { 2. Quiet } \\
\text { family } \\
\text { member } \\
\text { present }\end{array}$ & 5 & 4 & 55.75 & 3 & 3 & 5 & 5 \\
\hline $\begin{array}{l}\text { 3. Distressed } \\
\text { family } \\
\text { member } \\
\text { present }\end{array}$ & 5 & 0 & $\mathrm{~N} / \mathrm{A}$ & 1 & 1 & 5 & 5 \\
\hline $\begin{array}{l}\text { Test for } \\
\text { difference } \\
\text { between } \\
\text { scenarios }\end{array}$ & & $\begin{array}{l}p=0.05 \\
\text { (Fishers } \\
\text { exact test) }\end{array}$ & $\begin{array}{l}\mathrm{p}=0.57(\mathrm{t}- \\
\text { test) }\end{array}$ & $\begin{array}{l}p=0.14 \\
\text { (Fishers } \\
\text { exact test) }\end{array}$ & $\begin{array}{l}p=0.14 \\
\text { (Fishers } \\
\text { exact test) }\end{array}$ & N/A & N/A \\
\hline
\end{tabular}


The numbers are small in this analysis of observer assessment of the groups' performance under different scenarios. Nevertheless, the data suggests that groups with a distressed family member present performed less well than the other two groups (no family member or quiet family member present). No groups with a distressed family member present called for help following manikin arrest (a significant difference between groups was observed). They were also less likely to open the airway and check for breathing (though no significant difference between groups was observed with this small number of groups). All groups observed did compressions and ventilations. The average time taken to call for help was greater for groups with a quiet family member present (56 seconds) than for groups with no family member present (33 seconds); again this difference is not statistically significant.

\section{DISCUSSION}

We have assessed students' performance over three CPR cycles in three different simulated scenarios using data collected by resuscitation manikin software and by observers using a standardised form. In relation to BLS performance, we found a slight increase in the proportion of compressions that were of appropriate pressure when a distressed family member was present, whereas there was a significant improvement in the timing of compressions when a distressed family member was absent. The basic tasks of calling for help, opening airway and checking for breathing were completed most successfully by groups who either had no family member present or a quiet family member present. These groups moved more quickly through the tasks and started CPR much sooner without the presence of a family member to accommodate. In contrast, groups with a distressed family member present consistently omitted key aspects of the BLS protocol e.g. call for help. This suggests that distressed family member presence distracted students from performing tasks 
taught and assessed only two weeks before the study. Observer data availability for all three groups, including the quiet family member scenario, allows us to test this theory. The scenario where a non-distressed family member is present acts as a control for the effect of having an actor present. Although the observer data is limited by the small number of groups who performed each scenario, group performance appears to be adversely affected when the family member present was distressed i.e. performance was not simply related to the presence or absence of a family member.

Replication with a larger sample of registered nurses might confirm earlier work with healthcare professionals (Fernandez et al. 2009) which suggests that overtly distressed family member presence may have an impact on performance. In our study, several issues may have contributed to the poorer performance in groups with a distressed family member present. Students could have been inhibited, or perceived the call for help as exacerbating a situation for relatives who were already distressed. Likewise, checking vital signs sends signals to family members that all is not well. Students may have found this challenging when combined with their novice status, lack of confidence in their skills under pressure, and formative professional socialisation where they may feel uncomfortable asserting themselves with older actors.

However, this finding is not consistent across the whole scenario because there were some aspects where students with distressed family member performed equally well and in some cases better than their controls. Compression rates were generally good in both scenarios, yet the depth of compressions demonstrate some interesting differences. The group without a family member present were more likely to use extra force to apply a compression. In 
contrast, the group with a distressed family member were more likely to apply too little pressure, which may reflect a cautious approach in family member presence.

The research took place in a UK university nursing department with second year undergraduate adult nursing students. This research was designed to incorporate and be consistent with current thinking around simulation pedagogy (Berragan, 2011). The scenarios took place in dedicated simulation labs to replicate key aspects of practice situations (Okuda and Quinones, 2008). The complex nature of family witnessed resuscitation scenarios ensured that key elements of simulation practice were present. It used high fidelity manikins to provide realistic and consistent physiological cues for healthcare professionals to recognise and respond (Aggerwall et al. 2009). This allowed us to record and collect student actions in real-time as accurate and meaningful manikin feedback can be provided on all aspects of CPR (Solnick and Weiss, 2007). The need to perform BLS within a scenario and cooperate and work with others (including a relative) ensured that psychomotor skills were present (Ahn, \& Kim, 2015). Finally, using standardised manikin patient voices and having relatives present ensured the scenario was consistent with good simulation practice and design (Society for Simulation in Healthcare, 2015). We drew on evidence to prepare standardised patients, and actors playing relatives to replicate consistent responses across different scenarios (Levine and Swartz, 2008; Oh et al, 2015). Using human patient simulators and actors playing standardised relatives to create simulated family-witnessed resuscitation allows researchers to test and explore the complex emotional and social contexts in which psychomotor skills take place. 
This student group was targeted because they had completed 12 months of clinical practice and had sufficient experience to engage in simulation, but were still forming their skills and attitudes to this topic. Previous studies looking at performance studied samples of paramedics and medical students (Bjørshol et al., 2011; Fernandez et al., 2009). Nursing students have frequent and close proximity to patients and are often first responders initiating emergency care. Unlike Bjørshol et al. (2011) and Fernandez et al. (2009), this study restricted itself to BLS performance rather than advanced life support as this is expected of second year student nurses. Key outcome measures were restricted to compressions and ventilations. These key psychomotor skills are difficult to perform satisfactorily during hospital cardiac arrests (Abella et al., 2005). The study was scheduled to take place two weeks after the annual student BLS update. The findings have direct implications for student nurse education in terms of family presence effect on students' ability to carry out BLS, and delivery of correct compression pressure and timing. More frequent CPR scenarios in nurse education schedules would help build student confidence to support distressed family members, and provide experience to perform the necessary tasks in a distressed family 's presence.

\section{Limitations}

We pooled students from across two educational sites but the numbers available to participate were small for a RCT with three experimental arms. Despite this, clear patterns emerged when assessing observer-recorded outcomes across the three scenarios, and the statistically significantly findings based on the manikin-recorded outcomes suggest that our small study is not underpowered. 
There are a number of limitations due to the pragmatic nature of this trial, and the fact that it happened during teaching time. Not all students took part in the groups to which they were initially randomised (reasons for this are described above). The students are demographically very homogenous, and demographic information was not collected as part of the trial, so student characteristics in each trial arm cannot be formally compared. Therefore it is important to consider what effect, if any, deviations from the initial randomisation may have had on the comparability of the students performing the three scenarios in the trial. Student requests for different time slots were based purely on other commitments which prevented their attendance at their randomly allocated time; they were not based on knowledge of the allocated scenario or other factors such as friendship groups. Each scenario took place at each of the various time slots throughout the day, so there is no reason to believe that these swops would have led to differences between the student groups in each of the three scenarios. Several groups performed the scenario with three rather than four members due to non-attendance. This affected two of the groups without a family member present, one which had a quiet family member present, and none which had a distressed family present. It could be argued that the effect of having three rather than four team members might have either a positive effect on performance (e.g. easier to coordinate a small group) or a negative effect (e.g. less students to perform required tasks). Observer feedback data suggests that the smaller groups with no family member present appeared better organised and carried out their task quickly and efficiently. This latter point would be most relevant to groups with a distressed family relative, which were all comprised four students. A positive effect would bias the findings in support of better performance with no family member present, while a negative effect would bias the findings in support of better performance with a distressed family member present. 
We highlighted how manikin technical issues caused ventilation data (all groups) and compression data (groups with quiet family member present) to be eliminated, which limited the comparisons of quantitative outcomes recorded by the manikins that could be made. Observational data was more complete as the manikin did not arrest in only two cases. Although some of the observers may have been known to the students in advance, they only intervened when there was an equipment malfunction and to inform them when the scenario was at an end. The manikin data is likely to be more objective than the observer data, but both contribute to a consistent understanding of the effect of family-witnessed resuscitation on student nurses' performance.

Finally, we acknowledge the limitation that these students, because of their stage of training, have had less clinical exposure and therefore the application of these findings directly to the qualified population must be treated with caution. However we contend that the design and findings may have important contribution to make to further studies with a registered nurse population.

\section{CONCLUSION}

It appears that the presence of a distressed relative at the resuscitation of a loved one may adversely impact on student nurses' performance. Further work should be undertaken with students and the wider community of qualified professionals to explore whether experience and training can overcome some of these negative impacts. 
Funding: This project was funded by research grants from the Association for Simulated Practice in Healthcare and CAE Healthcare. There was no conflict of interest. 


\section{References}

Aggarwall, R., Mytton, O., Debrew, M., Hananel, D. Heydenburg, D., Issenberg, M., MacAulay, C., Mancini, E., Morimoto, T., Soper, N., Ziv, A., Rexnick, R., 2009. Training and simulation for patient safety. Quality and Safety in Health Care, 19, i34-i43. doi:10.1136/qshc.2009.038562

Abella, B.S., Sandbo, N., Vassilatos, P., 2005. Chest compression rates during cardiopulmonary resuscitation are suboptimal: A prospective study during in-hospital cardiac arrest. Circulation, 111, 428-434.

Ahn, M. \& Kim, H.Y. 2015 Implementation and outcome evaluation of high-fidelity simulation scenarios to integrate cognitive and psychomotor skills for Korean nursing students Nurse Education Today, 35 (5), 706-711

Basol, R., Ohman, K., Simones, J., \& Skillings, K., 2009. Using research to determine support for a policy on family presence during resuscitation. Dimensions in Critical Care Nursing, 28(5), 237-247.

Berragan, E. 2011 Simulation: An effective pedagogical approach for nursing? Nurse Education Today, 31 (7). pp. 660-663. ISSN 0260-6917 Available from: http://eprints.uwe.ac.uk/20108

Bjørshol, C. A., Myklebust, H., Nilsen, K. L. Hoff, T., Bjørkli, C. Illguth, E., Søreide, E., Sunde, K., 2011. Effect of socioemotional stress on the quality of cardiopulmonary resuscitation during advanced life support in a randomized manikin study. Critical Care Medicine, 39(2), 300-304.

Boyd, R., White, S., 2000. Does witnessed cardiopulmonary resuscitation alter perceived stress in accident and emergency staff? European Journal of Emergency Medicine, 7(1): 513.

Critchell, C.D., Marik, P.E., 2007. Should family members be present during cardiopulmonary resuscitation? A review of literature. American Journal of Hospice \& Palliative Care, 24(4), 311-317.

Coulter, A., and Collins, A., 2011. Making Shared Decision Making a Reality: No Decision about Me without Me. London: The King's Fund.

http://www.kingsfund.org.uk/sites/files/kf/Making-shared-decision-making-a-reality-paperAngela-Coulter-Alf-Collins-July-2011_0.pdf (last accessed 04/02/16).

Clark, A.P., Aldridge, M.D., Guzzetta, C.E., Nyquist-Heise, P., Reverend Mike Norris, Loper, P., Meyers, T.A., Voelmeck, W., 2005. Family presence during cardiopulmonary resuscitation. Critical Care Clinics of North America, 17(1), 23-32.

Demir, F., 2008. Presence of patients' families during cardiopulmonary resuscitation: Physicians' and nurses' opinions. Journal of Advanced Nursing, 63(4), 409-416.

Department of Health (2011) A framework for technology enhanced learning. DH Publications, London. http://www.dh.gov.uk/publications (Accessed 12/2/16) 
Eikeland, H.S., Bjørshol C.A., Rystedt, H., Friberg, F., Søreide, E., 2012. A comparative study of defibrillation and cardiopulmonary resuscitation performance during simulated cardiac arrest in nursing student teams. Scandinavian Journal of Trauma Resuscitation and Emergency Medicine, 2, 20-23.

Fernandez, R., Compton, S., Jones, K.A., \& Velilla, M.A., 2009. The presence of a family witness impacts physician performance during simulated medical codes. Critical Care Medicine, 37(6), 1956-1960.

Hanson, C., Strawser, D., 1992. Family presence during cardiopulmonary resuscitation: Foote Hospital emergency department's nine-year perspective. Journal of Emergency Nursing, 18(2), 104-106.

Health Education Training Institute (HETI). 2014. Simulation based education Professional entry student education and training. Available at: www.heti.nsw.gov.au. Accessed: 12/2/16

Jabre, P., Belpomme, V., Azoulay, E., Jacob, L., Bertrand, L., Lapostolle, F., Tazarourte, K., Bouilleau, G., Pinaud, V., Broche, C., Normand, D., Baubet, T., Ricard-Hibon, A., Istria, J., Beltramini, A., Alheritiere, A., Assez, N., Nace, L., Vivien, B., Turi, L., Launay ,S., Desmaizieres, M., Borron, S.W., Vicaut, E., Adnet, F., 2013. Family presence during cardiopulmonary resuscitation. New England Journal of Medicine, 368(11), 1008-18.

Koberic, S., Kaltwasser, A., Rothaug, O. and Albarran, J., 2010. Family-witnessed resuscitation: Experiences and attitudes of German intensive care nurses. Nursing In Critical Care, 15 (5), 241-250.

Akhu-Zaheya, L. M., Gharaibeh, M. K. Alostaz, z. M. 2012 Effectiveness of Simulation on Knowledge Acquisition, Knowledge Retention, and Self-Efficacy of Nursing Students in Jordan Clinical Simulation in Nursing e1-e8

Legare, F., Witteman, H., 2013. Shared Decision Making: Examining Key Elements and Barriers to Adoption into Routine Clinical Practice. Health Affairs, 32(2), 276-284.

Leighton, K., Scholl, K. 2009 Simulated Codes: Understanding the Response of Undergraduate Nursing Students Clinical Simulation in Nursing 5, e187-e194

Levine, A.I., Swartz, M.H., 2008. Standardized patients: the "other" simulation. Journal of Critical Care, 23, 179-184.

Madden E., Condon, C., 2007. Emergency nurses' current practices and understanding of family presence during CPR. Journal of Emergency Nursing, 33(5), 433-440.

McClement, S.E., Fallis, W.M., Pereira, A., 2009. Family presence during resuscitation: Canadian critical care nurses' perspectives. Journal of Nursing Scholarship, 41(3), 233-240. 
McGahey-Oakland, P.R., Lieder, H.S., Young, A., Jefferson, L.S., 2007. Family experiences during resuscitation at a children's hospital emergency department. Journal of Pediatric Health Care, 21(4), 217-225.

Okuda, Y., Quinones. J., 2008. The use of simulation in the education of emergency care providers for cardiac emergencies. International Journal of Emergency Medicine, 1, 73-77.

Oh, J. A., Jeon, k. D. \& Koh, M. S. 2015. The effects of simulation-based learning using standardized patients in nursing students: A meta-analysis Nurse Education Today 35(5) e6e15

Resuscitation Council UK Guidelines 2015 Summary of changes in basic life support and automated external defibrillation since the 2010 guidelines, available at: https://www.resus.org.uk/resuscitation-guidelines/adult-basic-life-support-and-automatedexternal-defibrillation/ (accessed $12^{\text {th }}$ of December 2015)

Solnick, A., Weiss, S., 2007. High Fidelity Simulation in Nursing Education: A Review of the Literature Clinical simulation in Nursing 3(1), e41-e45.

Society for Simulation in Healthcare 2015. About simulation. Retrieved from http://www.ssih.org/ About-Simulation

StataCorp, 2011. Stata Statistical Software: Release 12. College Station, TX: StataCorp, L.

Tinsley, C., Hill, J.B., Shar, J., Zimmerman, G., Wilson, M., Freier, K., Abd-Allah, S., 2008. Experience of families during cardiopulmonary resuscitation in a pediatric intensive care unit. Pediatrics, 122(4), e799-e804.

Walker, W., 2007. Accident and emergency staff opinion of the effects of family presence during adult resuscitation: critical literature review. Journal of Advanced Nursing, 61(4), 348362.

Wagner, J. M., 2004. Lived experience of critically ill patients' family members during cardiopulmonary resuscitation. American Journal of Critical Care, 13(5), 416-20. 